\title{
Adherence to breast cancer guidelines is associated with better survival outcomes: a systematic review and meta-analysis of observational studies in EU countries
}

Ignacio Ricci-Cabello ${ }^{1,2,3}$, Adrián Vásquez-Mejía ${ }^{4}$, Carlos Canelo-Aybar ${ }^{3,5}$, Ena Niño de Guzman ${ }^{5^{*}}$, Javier Pérez-Bracchiglione ${ }^{6}$, Montserrat Rabassa ${ }^{5}$, David Rigau ${ }^{5}$, Ivan Solà ${ }^{3,5}$, Yang Song ${ }^{5}$, Luciana Neamtiu 7 , Elena Parmelli ${ }^{7}$, Zuleika Saz-Parkinson ${ }^{7^{*}}$ (i) and Pablo Alonso-Coello ${ }^{3,5}$

\begin{abstract}
Background: Breast cancer (BC) clinical guidelines offer evidence-based recommendations to improve quality of healthcare for patients with or at risk of BC. Suboptimal adherence to recommendations has the potential to negatively affect population health. However, no study has systematically reviewed the impact of BC guideline adherence -as prognosis factor- on BC healthcare processes and health outcomes. The objectives are to analyse the impact of guideline adherence on health outcomes and on healthcare costs.

Methods: We searched systematic reviews and primary studies in MEDLINE and Embase, conducted in European Union (EU) countries (inception to May 2019). Eligibility assessment, data extraction, and risk of bias assessment were conducted by one author and crosschecked by a second. We used random-effects meta-analyses to examine the impact of guideline adherence on overall survival and disease-free survival, and assessed certainty of evidence using GRADE.
\end{abstract}

Results: We included 21 primary studies. Most were published during the last decade (90\%), followed a retrospective cohort design (86\%), focused on treatment guideline adherence (95\%), and were at low (80\%) or moderate (20\%) risk of bias. Nineteen studies (95\%) examined the impact of guideline adherence on health outcomes, while two (10\%) on healthcare cost. Adherence to guidelines was associated with increased overall survival $(\mathrm{HR}=0.67,95 \% \mathrm{Cl} 0.59-0.76)$ and disease-free survival ( $\mathrm{HR}=0.35,95 \% \mathrm{Cl} 0.15-0.82)$, representing 138 more survivors (96 more to 178 more) and 336 patients free of recurrence (73 more to 491 more) for every 1000 women receiving adherent CG treatment compared to those receiving non-adherent treatment at 5 years follow-up (moderate certainty). Adherence to treatment guidelines was associated with higher costs, but adherence to follow-up guidelines was associated with lower costs (low certainty).

(Continued on next page)

\footnotetext{
* Correspondence: enino@santpau.cat; zuleika.saz-parkinson@ec.europa.eu

${ }^{5}$ Iberoamerican Cochrane Centre - Department of Clinical Epidemiology and

Public Health, Biomedical Research Institute Sant Pau (IIB Sant Pau), Sant

Antonio María Claret 167, 08025 Barcelona, Spain

${ }^{7}$ European Commission, Joint Research Centre (JRC), Ispra, Italy

Full list of author information is available at the end of the article
}

C C The Author(s). 2020 Open Access This article is licensed under a Creative Commons Attribution 4.0 International License, which permits use, sharing, adaptation, distribution and reproduction in any medium or format, as long as you give appropriate credit to the original author(s) and the source, provide a link to the Creative Commons licence, and indicate if changes were made. The images or other third party material in this article are included in the article's Creative Commons licence, unless indicated otherwise in a credit line to the material. If material is not included in the article's Creative Commons licence and your intended use is not permitted by statutory regulation or exceeds the permitted use, you will need to obtain permission directly from the copyright holder. To view a copy of this licence, visit http://creativecommons.org/licenses/by/4.0/ The Creative Commons Public Domain Dedication waiver (http://creativecommons.org/publicdomain/zero/1.0/) applies to the data made available in this article, unless otherwise stated in a credit line to the data. 
(Continued from previous page)

Conclusions: Our review of EU studies suggests that there is moderate certainty that adherence to BC guidelines is associated with an improved survival. BC guidelines should be rigorously implemented in the clinical setting.

Trial registration: PROSPERO (CRD42018092884).

Keywords: Breast cancer, Clinical guidelines, Adherence, Survival, Systematic review

\section{Background}

Breast cancer is the world's most common cancer in women with an estimated 2.08 million new cancer cases diagnosed in 2018, accounting for $24.2 \%$ of all cancers [1]. The illness is diagnosed more frequently in developed countries. According to the European Cancer Information System, more than 400,000 incident female breast cancer cases and 98,000 deaths were estimated in the European Union (EU28) for 2018 [2] (Additional file 1). Preventing, diagnosing and treating breast cancer is, therefore, an important priority for health policymakers. Treatment procedures have changed dramatically over recent years. As new and more precise diagnostic strategies have shown, treatment for early and metastatic breast cancer has improved [3-7]. Similarly, advances in breast cancer screening and treatment have reduced breast cancer mortality across the age spectrum in the past decade [8-10].

Clinical guidelines (CGs) are statements that include recommendations intended to optimise patient care [11]. Evidence-based high-quality CGs are becoming increasingly available as a result of recent advances in health services research [12]. However, the effectiveness of the CGs heavily depends not only on their quality but also on how they are implemented, and embedded in clinicians' routine clinical practice [13].

Since CGs recommendations should be based on best available evidence, adherence to CGs is expected to result in better patient outcomes. However, most CGs rely on evidence from clinical trials, which are usually performed with relatively small samples at sites with experienced investigators and highly selected participants, and therefore are at risk of overestimating benefits and underestimating harms [14]. Moreover, they are generally conducted in high-income countries, and, as a consequence, tend to be very resource-intensive [15]. Therefore, the external validity and clinical utility of their recommendations must be confirmed in real clinical practice. Moreover, non-adherence can be due to valid reasons (mainly related to contraindications and patient preferences), and therefore many CGs deviations are intentional and do not necessarily impact negatively on the quality of care [16].

Some studies have shown that CGs adherence can have a positive impact on patient outcomes in the field of breast cancer [17-20]. On the other hand, some authors have suggested a paradox by which guideline deviations would contribute to increased survival of patients with breast cancer (proposing that observed improvements in health outcomes during the last two decades may be more due to higher resource availability rather than adherence to guidelines) [21, 22]. To the best of our knowledge, no previous systematic review has examined the impact of breast cancer CGs adherence on health outcomes.

Adherence to breast cancer CGs might behave as a prognostic factor for health outcomes. A prognosis factor is any measure that, among people with a given health condition, is associated with a subsequent clinical outcome [23]. Even though most researched prognostic factors are biomarkers, or patient's characteristics, these may also be measured outside the individual, at an ecological level, such as health care access, quality of care, and breast cancer guidelines adherence in which the exposure of individuals is inferred [23]. The objective of this systematic review is two-fold: i) to identify if adherence (compared to non-adherence) to CGs impacts on patient-related outcomes and ii) to identify if adherence (compared to non-adherence) to CGs impacts on healthcare costs.

\section{Methods}

We conducted a systematic review following the standard Cochrane Collaboration methods [24] and adhering to the PRISMA statement reporting guidelines [25]. We registered the research protocol in PROSPERO (CRD42018092884).

\section{Data sources and searches}

We designed search strategies (May 2019) to search Embase (accessed through Ovid) and MEDLINE (PubMed). In a first step we focused the search to identify systematic reviews as a source of primary studies, and then we searched primary studies. Additional file 2 shows the search algorithms.

\section{Eligibility of studies}

We used the PICO (Population, Intervention, Comparison, Outcome) framework to guide our eligibility criteria (Table 1). We included observational studies (beforeafter, cohort, case-control, and cross-sectional studies) examining the impact of CGs adherence on: 1) breast cancer patient-related outcomes (overall survival, disease-free survival, quality of life, incidence-based mortality, harm), 
Table 1 Structured clinical question

\begin{tabular}{llll}
\hline Population & Intervention & Comparison & Outcomes $^{\mathbf{a}}$ \\
\hline Healthcare professionals involved & Adherence to breast cancer & Non-adherence to breast cancer & 1) Impact on patient-related outcomes \\
in breast cancer care (all processes) & CGs in the process of care & CGs in the process of care. & -Overall survival \\
& & & -Disease-free survival \\
& & -Quality of life \\
& & -Incidence based-mortality \\
& & $\cdot$ Harm \\
\hline
\end{tabular}

aist of prioritised outcomes produced as a result of agreement between JRC experts and CCIB members

and 2) healthcare costs. We included studies conducted only in the 27 countries members of the European Union at the time the review was conducted (as this systematic review was conducted within the European Commission Initiative on Breast Cancer). Multicounty studies conducted in EU and non-EU countries were excluded. The list of the 27 countries included is available in Additional file 3. We only included studies published in English. First, for calibration purposes two reviewers (IRC and AVM) independently screened $20 \%$ of the search results based on title and abstract and selected the references to be assessed based on full text. Then, the remaining $80 \%$ of the references were screened by a senior systematic reviewer (IRC). All references selected for full-text assessment were double-checked by a second author (AVM). The level of agreement between both reviewers was $85 \%$. Disagreements were solved by discussion or with the help of a third author (ENDG).

\section{Data extraction and risk of bias assessment}

We extracted and described in tables, the main characteristics of included studies (e.g. country, publication year, guideline scope, study design, aim, and year of study, number of patients, patient's characteristics, and adherence definition), and of the outcomes of interest. Data extraction was conducted in pairs, one author (IR) conducted the first extraction, subsequently, a second author (JPB) cross-checked the extracted data. If necessary, the corresponding authors of the studies included were contacted to retrieve further information.

For risk of bias assessment, we used specific tools depending on the study design. For longitudinal studies (including both prospective and retrospective follow-up designs) we used the Newcastle - Ottawa Quality Assessment Scale [26], which contains nine items classified in three main domains: selection, comparability, and outcome. The studies are graded according to a score from 0 (highest risk of bias) to 9 (lowest risk of bias). The following cut-off points were applied: $<5$, high risk of bias; $5-7$, moderate risk of bias; $>7$, low risk of bias. For non-controlled before-after studies, we used the Quality
Assessment Tool for Before-After (Pre-Post) Studies With No Control Group [27]; this tool includes 12 criteria, each of them rated as presence or absence of risk of bias. One author (IRC) carried out the risk of bias assessment, and a second author (AVM) cross-checked this assessment. Disagreements were solved by discussion or with the help of a third author.

\section{Data synthesis and analysis}

Survival measures (overall survival and disease-free survival) and impact on health cost were compared between adherent and non-adherent groups of patients. For survival outcomes, only studies reporting HRs using Cox adjusted models with at least 5 years of follow up were pooled, using the Der Simonian and Laird random effects model [28]. Statistical heterogeneity was assessed using Cochran $\mathrm{Q}$ and $\mathrm{I}^{2}$ measure. An $\mathrm{I}^{2}$ value above 50 and $75 \%$ was predefined as moderate and high heterogeneity, respectively [29]. If selected studies had a similar source of data, (i.e. the BRENDA cohort [30]) to avoid the risk of double counting populations or events, we selected the cohort values with the longest follow-up and with more complete data reporting. Results were expressed as $\mathrm{HR}$ and the related 95\% CI, a $\mathrm{HR}<1$ denote advantage for adherence and HR $>1$ denotes advantage for non-adherence to CGs. The anticipated absolute effects estimates were measured as risk differences. We collected the mortality and recurrence rates for a followup period of 60 months in both the intervention (i.e. adherent to CGs) and control (i.e. non-adherent to CGs) groups. The estimation of risk differences was performed indirectly from the pooled hazard ratios and the estimation of the baseline risk. For the latter, data was obtained from Kaplan Meier survival curves from the control groups [31]. We used Review Manager v.5.3 [32] for the estimation of pooled hazard ratios, and we used GRAD Epro [33] for the estimation of the absolute difference of events. We narratively synthesised findings for impact on healthcare costs, and survival outcomes for the remaining studies not included in the meta-analysis. 
To assess the certainty of evidence we applied the Grading of Recommendations Assessment, Development and Evaluation (GRADE) approach [12]. We downgraded the certainty of the evidence based on the assessment of: study limitations, inconsistency of results, indirectness of evidence, imprecision, and reporting bias. GRADE principles apply also to prognostic questions [34]. In contrast to treatment effects questions, in prognosis questions, cohorts with a prospective design, initially provide high certainty as they enable optimal measurement of predictors and outcomes [35]. Quality of evidence is classified in four categories: high (which indicates we are very confident that the true prognosis lies close to that of the estimate); moderate (we are moderately confident that the true prognosis is likely to be close to the estimate, but there is a possibility that it is substantially different); low (our confidence in the estimate is limited: the true prognosis may be substantially different), and; very low quality (any estimate of effect is very uncertain) [34]. We report the main findings both narratively and as tabulated summaries.

\section{Results}

\section{Search results}

The eligibility process of the original studies is summarised in a PRISMA flowchart (Fig. 1). We retrieved a total of 8137 unique citations from database searches, which were reviewed along with another 193 references identified from ten identified systematic literature reviews. We selected 112 references for review at the fulltext level. Of these, we excluded 91 publications (reasons for exclusion available in Additional file 3), and finally included 21 studies [17-22, 30, 36-49].

\section{Characteristics of the included studies}

Most of included studies were conducted in Germany (15/ $21 ; 71 \%)$ and were published during the last decade (19/21, $90 \%)$. Most were retrospective cohort studies (18/21, 86\%); of these, 13 were single cohorts (BRENDA study [30]) but included different periods and/or addressed different clinical questions; three were non-controlled before-after studies. Two studies examined the impact of adherence to CGs on healthcare costs, whereas 20 studies examined the impact on health outcomes (most frequently survival related measures). (Tables $2 \mathrm{a}$ and $2 \mathrm{~b}$, Additional file 4). No studies were identified examining the rest of the outcomes considered in this review (quality of life, incidence-based mortality, and harm).

Almost all studies $(n=20)$ examined the impact of adherence to treatment guidelines, two also addressed adherence to diagnostic guidelines and one addressed adherence to guidelines for follow-up (Table 3).

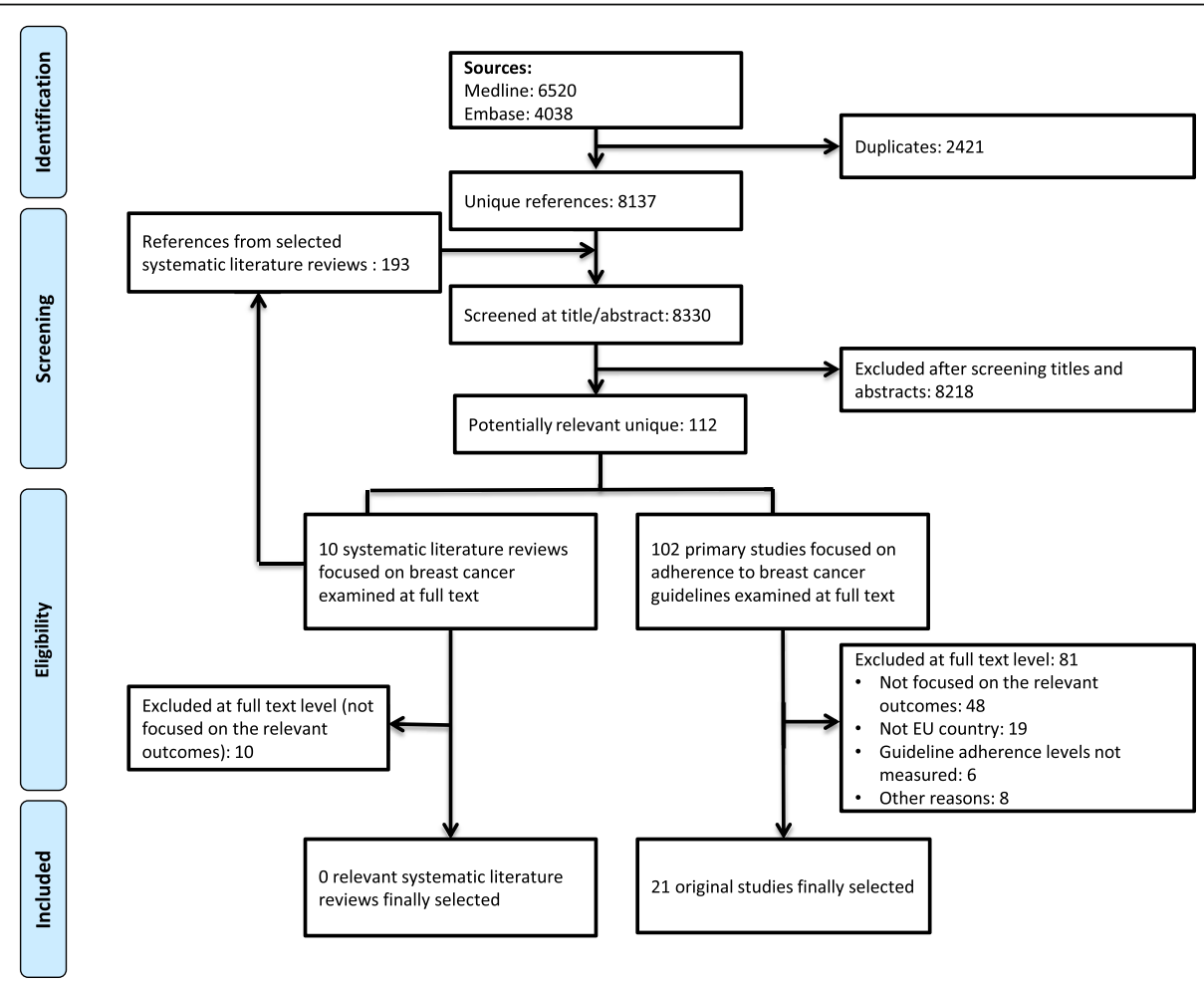

Fig. 1 PRISMA flowchart describing selection of included systematic reviews and original studies 


\section{Risk of bias assessment}

Out of the 21 studies included, 17 presented low risk of bias $[17,20-22,36,37,39-44,46-49]$ and four presented moderate risk of bias $[18,19,38,45]$. The most common reasons for risk of bias were related to the source of the non-exposed cohort, outcome assessment, and adequacy of follow-up (Tables $2 \mathrm{a}$ and $2 \mathrm{~b}$, Additional file 4).

\section{Impact on patient outcomes \\ Overall survival}

The random effects meta-analysis of four studies [17, 40, 49,50 ] with 15,974 patients followed up for a median of 5 years (Fig. 2, Table 3), showed that adherence to breast

Table 2a Characteristics of the included studies $(n=21)$

\begin{tabular}{|c|c|c|}
\hline Study characteristics & n (\%) & References \\
\hline \multicolumn{3}{|l|}{ Country } \\
\hline France & $2(10 \%)$ & {$[38,39]$} \\
\hline Germany & 15 (71\%) & {$[18-22,30,37,41-43,45-49]$} \\
\hline Italy & $2(10 \%)$ & {$[17,40]$} \\
\hline Netherlands & $2(10 \%)$ & {$[36,44]$} \\
\hline \multicolumn{3}{|l|}{ Publication year } \\
\hline 2015-2019 & $8(35 \%)$ & {$[17-22,45,49]$} \\
\hline 2009-2014 & $11(52 \%)$ & {$[30,40-44][37,39,46-48]$} \\
\hline$\leq 2008$ & $2(10 \%)$ & {$[36,38]$} \\
\hline \multicolumn{3}{|l|}{ Study design } \\
\hline $\begin{array}{l}\text { Non-controlled } \\
\text { before-after study }\end{array}$ & $3(14 \%)$ & {$[21,38,40]$} \\
\hline $\begin{array}{l}\text { Retrospective } \\
\text { cohort study }\end{array}$ & $18(86 \%)$ & {$[17-20,22,30,36,37,39,41-49]$} \\
\hline \multicolumn{3}{|l|}{ Guideline scope } \\
\hline Diagnosis & $2(10 \%)$ & {$[17,40]$} \\
\hline Follow-up & $1(5 \%)$ & [38] \\
\hline Treatment & 20 (95\%) & {$[17-22,30,36,37,39-49]$} \\
\hline \multicolumn{3}{|l|}{ Outcomes $\neq$} \\
\hline Overall survival & $18(86 \%)$ & {$[12-17,24-27,29,31-37,49]$} \\
\hline Disease free survival & $16(76 \%)$ & {$[13-15,17,24,26,28,29,31-37,49]$} \\
\hline $\begin{array}{l}\text { Costs associated to } \\
\text { CGs adherence }\end{array}$ & $2(10 \%)$ & {$[38,39]$} \\
\hline Quality of life & $0(0 \%)$ & - \\
\hline $\begin{array}{l}\text { Incidence-based } \\
\text { mortality }\end{array}$ & $0(0 \%)$ & - \\
\hline Harm & $0(0 \%)$ & - \\
\hline \multicolumn{3}{|l|}{ Risk of bias } \\
\hline Low & 17 (81\%) & {$[17,20-22,36,37,39-44,46-49]$} \\
\hline Moderate & $4(20 \%)$ & {$[18,19,38,45]$} \\
\hline High & $0(0 \%)$ & - \\
\hline
\end{tabular}

\# Percentages exceed $100 \%$ because the categories are not mutually exclusive (i.e. some studies involved more than one type of guideline and more than one type of outcome) cancer CGs was associated with better overall survival rates $\left(\mathrm{HR}=0.67(95 \% \mathrm{CI} 0.59\right.$ to 0.76$\left.), \mathrm{I}^{2}: 0 \%\right)$. This means that for every 1000 patients, 129 more patients (from 91 more to 165 more) would potentially survive in the group of patients managed in compliance with breast cancer CGs, compared to those who were not (non-adherent group). The certainty of evidence for adherence to CGs as a prognosis factor for overall survival was moderate due to risk of bias (studies relied only on the accuracy of medical records).

Additionally, another 18 studies not meeting the criteria for performing a meta-analysis as specified in the methods section, assessed this outcome. Their characteristics and main results are available in Additional files 4 and 5. A direct association between adherence to breast cancer CGs and better overall survival was more frequently observed regardless of the study period [22], the use of different cut-offs or number of deviations to CGs recommendations used to determine adherence [17, 42, 48] and patient's age [17, 18, 37, 41, 44, 45]. Although non-adherence was associated with lower survival rate both in triple negative breast cancer (TNBC) and nonTNBC patients, this association was stronger in TNBC than in non-TBNC patients $[19,43]$. Seven studies explored adherence by treatment modality $[18,19,30,37$, $43,47,48]$, revealing that there was better overall survival in patients receiving CG-compliant treatments for breast-conserving therapy, chemotherapy, endocrine therapy, and radiotherapy. One before after study did not find significant differences in survival rates comparing adherent versus non-adherent groups [21].

\section{Disease-free survival}

The random effects meta-analysis of three studies followed up a median of 5 years with 9224 patients [20, 36, 49] (Fig. 3, Table 3) showed better disease-free survival rates in patients receiving CG recommended treatment compared to those not receiving CG recommended treatment ( $\mathrm{HR}=0.35$ (95\% CI from 0.15 to $0.82) ; \mathrm{I}^{2}=96 \%$ ). This means that for every 1000 women there were 336 more women free of recurrence (73 more to 491 more) in patients managed in compliance with breast CGs compared to those who were not. The certainty of evidence for adherence to breast cancer CGs as a prognosis factor for disease-free survival was moderate. As in overall survival, we considered rating down our confidence by one level for risk of bias for the same reason (Table 3).

Additionally, this outcome was reported in another 15 studies not meeting the criteria for performing a metaanalysis as specified in the methods section. An association between adherence to breast cancer CGs and better disease-free survival was observed consistently regardless of the study period [22, 47], use of different 
Table $\mathbf{2 b}$ Characteristics of the clinical practice guidelines examined by the included studies

\begin{tabular}{|c|c|c|c|}
\hline Author/Year/Reference & $\begin{array}{l}\text { Scope of the } \\
\text { guideline(s) }\end{array}$ & $\begin{array}{l}\text { Type of health care recommendation } \\
\text { adherence was studied }\end{array}$ & Guidelines studied \\
\hline Andreano 2017 [17] & $\begin{array}{l}\text { National (Italian) guideline } \\
\text { and European guidelines* }\end{array}$ & Diagnosis and treatment (generic) & NICE guideline $a$; ESMO guideline $b$ \\
\hline de Roos 2005 [36] & National (Dutch) & $\begin{array}{l}\text { Treatment (treatment of patients } \\
\text { with DCIS) }\end{array}$ & Otter $2003 c$ \\
\hline Ebner, Hancke 2015 [18] & National (German) & Treatment (generic) & S3 guideline $d$ \\
\hline Ebner 2015 [19] & National (German) & Treatment (generic) & S3 guideline d \\
\hline Hancke 2010 [37] & $\begin{array}{l}\text { National (German) and } \\
\text { international guidelines* }\end{array}$ & Treatment (generic) & 2005 St Gallen consensus e; S3 guideline d \\
\hline Jacke 2015 [21] & National (German) & Treatment (generic) & S3 guideline $d$ \\
\hline Mille 2000 [38] & Regional (French) & Follow-up (post therapeutic follow-up) & Centre Régional Léon Bérard guidelines f \\
\hline Poncet 2009 [39] & $\begin{array}{l}\text { National and regional } \\
\text { (French) guidelines }\end{array}$ & $\begin{array}{l}\text { Breast cancer treatment (specific for } \\
\text { trastuzumab treatment) }\end{array}$ & $\begin{array}{l}\text { French post licensing guidelines (2001), } \\
\text { regional clinical guidelines published by } \\
\text { the regional oncology care network called } \\
\text { "Convergence" in the French Rhone-Alpes } \\
\text { area (no additional information provided). }\end{array}$ \\
\hline Sacerdote 2013 [40] & Regional (Italy) guidelines & Treatment (generic) & Piedmont Clinical Practice Guideline g \\
\hline Schwentner 2012 [43] & National (German) & Treatment (adjuvant) & S3 guideline $d$ \\
\hline Schwentner 2012 [42] & National (German) & Treatment (generic) & S3 guideline $d$ \\
\hline Schwentner 2013 [41] & National (German) & Treatment (generic) & S3 guideline $d$ \\
\hline Van de Water 2012 [44] & National (Dutch) & $\begin{array}{l}\text { Treatment (guidelines for breast and } \\
\text { axillary surgery, radiotherapy, } \\
\text { chemotherapy and endocrine therapy) }\end{array}$ & Dutch guideline $h$ \\
\hline Van Ewijk 2015 [45] & National (German) & Treatment (adjuvant treatment) & S3 guideline $d$ \\
\hline Varga 2010 [46] & National (German) & $\begin{array}{l}\text { Treatment (treatment of early-onset } \\
\text { breast cancer) }\end{array}$ & S3 guideline d \\
\hline Wollschlager 2017 [20] & National (German) & Treatment (guidelines for adjuvant treatment) & S3 guideline $d$ \\
\hline Wockel, Kurzeder et al. 2010 [48] & $\begin{array}{l}\text { National (German) and } \\
\text { international guidelines* }\end{array}$ & Treatment (generic) & 2005 St Gallen consensus e; S3 guideline d \\
\hline Wockel, Varga et al. 2010 [47] & $\begin{array}{l}\text { National (German) and } \\
\text { international guidelines* }\end{array}$ & Treatment (generic) & 2005 St Gallen consensus e; S3 guideline d \\
\hline Wolters 2015 [22] & National (German) & Treatment (adjuvant treatment) & S3 guideline $d$ \\
\hline Wockel 2014 [30] & National (German) & Treatment (generic) & S3 guideline $d$ \\
\hline Wimmer 2019 [49] & National (German) & Treatment (radiotherapy) & S3 guideline d \\
\hline
\end{tabular}

* adherence to recommendations from two different guidelines examined in this study

a, Early and locally advanced breast cancer diagnosis and treatment: full guideline. National Collaborating Centre for Cancer, Cardiff https://www.nice. org.uk/guidance/cg80/resources/early-and-locallyadvanced- breast-cancer-diagnosis-and- reatment-975,682,170,565

b, Senkus E, Kyriakides S, Ohno S et al. (2015) Primary breast cancer: ESMO Clinical Practice Guidelines for diagnosis, treatmentand follow-up. Ann Oncol 26:v8-v30. doi:https://doi.org/10.1093/annonc/ mdv298

c, Otter R (ed) (2003) Richtlijnen voor diagnostiek en behandeling van premaligne en maligne aandoeningen in de IKN-regio 2003 pp. 338-339.

Groningen: IKN; ISBN 90-74,114-25-3

d, Kreienberg K, Kopp I, Lorenz et al. Interdisciplinary S3 Guidelines for the diagnosis and treatment of breast cancer in women. German Cancer Society. 2004

e, Goldhirsch A, Glick JH, Gelber RD et al. Meeting highlights: international expert consensus on the primary therapy of early breast cancer 2005. Ann Oncol 2005; 16: 1569-1583. 9

f, Centre Régional Léon Bérard, Réseau Oncora: The'saurus ONCORA en Cancérologie. Paris, France, Arnette Blackwell, 1997, p 374

g, Regione Piemonte Assessorato Sanità, Commissione Oncologica Regionale, Centro di Riferimento per l'Epidemiologia e la Prevenzione Oncologica in Piemonte: Tumore della mammella - linee guida clinico organizzative per la

Regione Piemonte. 2002

h, Oncoline. Dutch National Breast Cancer Guidelines. http://www.oncoline.nl/mammacarcinoom

cut-offs to determine adherence [43, 47, 48], patient's age $[18,41]$ and subtype of tumour [42, 43]. Subgroup analyses showed that adherence to recommendations in CGs was directly associated with better $(p<0.05)$ disease free-survival for most modalities of therapy $[18,19,30$, $47,48]$. Women over 70 years of age less often $(p<0.05)$ received recommended breast-conserving therapy (7079 years: $74-83 \%$; $>79$ years: $54 \%)$ than women aged $\leq 69$ years (93\%) [37] (Additional file 5). The included studies did not report relevant data for the rest of the patient-important outcomes of interest (quality of life, incidence based-mortality, and harm). 


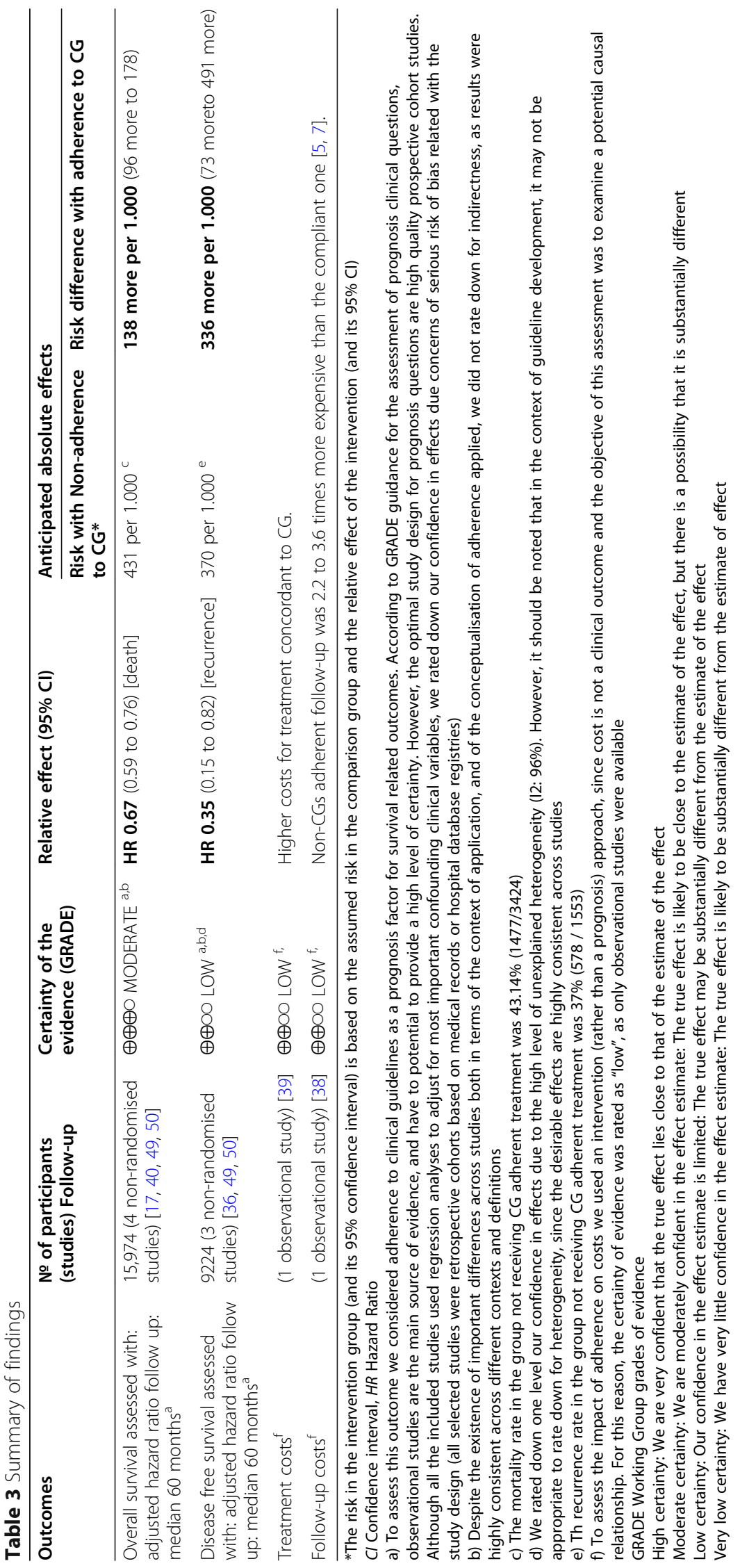




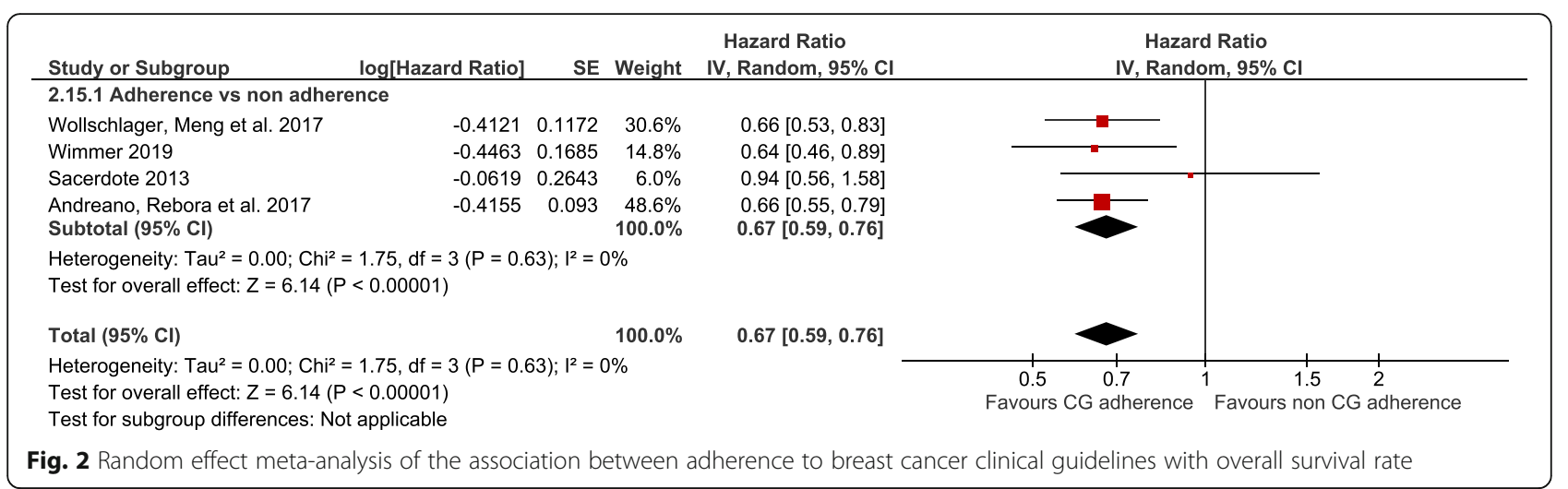

\section{Impact on health care cost}

Poncet et al. (2009) observed that treatment costs with trastuzumab per patient and per year were higher for patients receiving CGs-concordant treatment than for patients receiving CGs discordant treatment (EUR 54975 vs. EUR 44186, respectively). The main reason for this difference was the treatment cost since the type of molecules for combination with trastuzumab recommended in the CGs were more expensive than other alternatives not stated in the CGs [39]. Mille et al. (2000) observed that, in patients with localised breast cancer, the expenditure associated to CGs concordant healthcare (consultations and examinations) was consistently lower (from 2.2 to 3.6 times lower) compared to CGs discordant healthcare. Unjustified examinations mainly explained this difference [38]. The certainty of the evidence for the impact on health care costs was low both for adherence to treatment guidelines and for adherence to follow-up guidelines because in both cases only observational studies were available (Table 3, Additional file 4).

\section{Discussion}

\section{Main findings}

In this systematic review and meta-analysis, we observed that there is moderate certainty that adherence to breast cancer CGs by healthcare providers is associated with a substantial increase in overall survival and disease-free survival. We observed that for every 1000 women managed according to CGs compared to those that were not (non-adherent), there were 138 more survivors and 336 more free of recurrence patients over 5 years of follow-up.

\section{Our results in the context of previous research}

Previous systematic reviews have shown that adherence to breast cancer CGs [51] and other types of cancer CGs $[52,53]$ remains suboptimal. Sustainable use of CGs is also notably suboptimal, with studies showing up to a $50 \%$ decrease in adherence after 1 year of implementation [54]. Suboptimal adherence to CGs could increase healthcare costs if healthcare resources are overused (e.g. overtreatment, overuse of diagnostic or screening techniques), but also if they are underused (i.e. increased costs to cover the additional healthcare needs that people may face with worsening conditions due to provision of inadequate care). In our review, we identified no solid evidence about the economic impact of non-adherence to breast cancer CGs. This finding supports the results from a previous systematic review, which noted an absence of robust economic evaluations of the impact of CGs implementation [55].

As far as we know, no previous systematic review has examined the impact of breast cancer CGs adherence as a prognosis factor of health outcomes. Our findings, however, resonate with those from a previous systematic

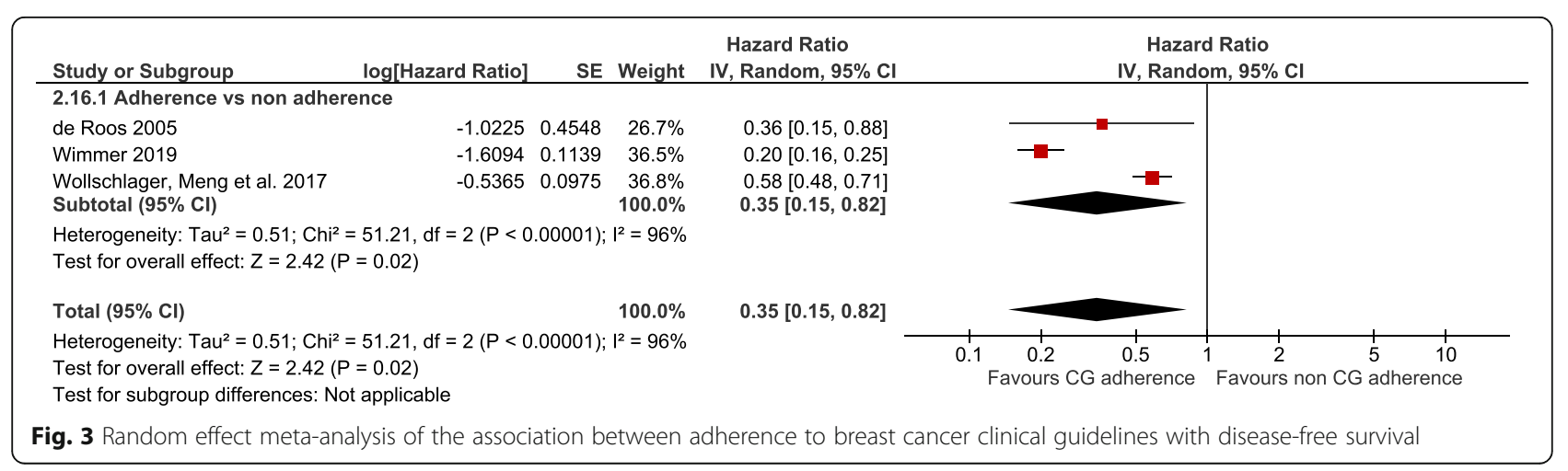


review of adherence to gynaecologic cancer surgery CGs, which suggested that adoption of CGs was an effective tool for disease control; noting that CGs adherence should be considered as a process measure of quality cancer care [56]. A number of non-condition specific systematic reviews have evaluated the effectiveness of CGs [57-61]. These reviews (which differed in terms of population, interventions, and outcomes considered) show a trend that supports that CGs improve patient outcomes. However, they consistently noted that the amount and quality of evidence upon which to develop their conclusions were very poor and that more methodologically robust studies are needed to build a stronger evidence base around the impact of CGs adherence.

\section{Strengths and limitations}

Our review has several strengths. We followed a robust methodology to produce quantitative estimates of the impact of CGs adherence, conducting metaanalyses, evaluating for the first time, the impact of adherence to breast cancer CGs on patient-important health outcomes (i.e., outcomes that patients value directly, instead of surrogate, outcomes that clinicians may consider important) [62]. We conducted detailed data extraction from selected studies and used specific tools for risk of bias assessment. We followed best practice for evidence assessment, using summary of finding tables and GRADE to assess the certainty of effects [63].

Our study has some limitations. First, we searched two bibliographic databases and only one author conducted the initial screening based on titles and abstracts (i.e., only $20 \%$ of the references were cross-checked by a second reviewer). Although data extraction and risk of bias assessment process was conducted in pairs using a cross-checking strategy rather than conducting them independently. by; these aspects could have limited our ability to identify additional studies. However, we included studies from four countries in the EU, with consistent findings. It is therefore unlikely that additional studies would have substantially changed the results. Second, we restricted the selection of studies to those published in English and in EU countries (due to the scope of the study), and most (71\%) of the studies identified were conducted in a single country (Germany). This may limit the generalisability of our findings, which may not represent other contexts with different CGs development methods or implementation strategies. And third, since we framed our question as a prognosis question, our conclusions can only suggest an association rather than imply causality. Moreover, the absolute effect size of the risk of death or recurrence expressed should be interpreted with caution. The number of events will vary greatly depending on the time chosen; in this work we selected the estimates at 5 years of follow up. The estimation of absolute effect estimates was calculated indirectly using the pooled hazard ratios adjusted for prognostic factors and the number of events in the control groups. We are aware that selecting different baseline risks according to different settings or types of population would vary substantially the number of events.

\section{Implications for practice and research}

The evidence identified in our review supports, with moderate certainty, that adherence to breast cancer CGs is associated with greater survival and disease-free survival. In light of our findings, the use of CGs should be more widely implemented. However, the way in which guideline adherence and implementation should be effectively enhanced remains uncertain: although several strategies have been proposed, and educational interventions are promising $[64,65]$, the evidence base about the efficacy of the proposed interventions is still limited [66]. Addressing this knowledge gap should be a priority for future research [67-69].

Our study provides valuable information, especially for health policymakers, to support the development of strategies to implement CGs and/or reinforce CGs-adherence in breast cancer care. Greater use of explicit theory to understand barriers, design interventions, and explore mediating pathways and moderators is also much needed to advance in this area [70, 71]. In addition, the certainty of evidence in relation to the impact of adherence to CGs on health care cost was low, and the available information is based on studies published more than a decade ago, when the cost of Trastuzumab was considerably more expensive than nowadays. Robust economic studies evaluating the impact of adherence to CGs on health care costs are needed to progress in this area.

\section{Conclusion}

Our systematic review of studies conducted in the EU shows that there is moderate certainty that adherence to breast cancer guidelines is associated with improved overall and disease-free survival. The impact on cost is inconclusive (low certainty). Breast cancer guidelines should be rigorously implemented in the clinical setting.

\section{Supplementary information}

Supplementary information accompanies this paper at https://doi.org/10. 1186/s12913-020-05753-X.

Additional file 1. Figure 1A. Breast cancer mortality in Europe 2018 estimates. Figure 1B. Breast cancer incidence in Europe 2018 -estimates

Additional file 2. Search strategy

Additional file 3. Excluded studies with reasons for exclusion 
Additional file 4. Characteristics of the included studies

Additional file 5. Adherence definitions and main findings

\section{Abbreviations}

CGs: Clinical guidelines; Cl: Confidence interval; EU: European Union; HR: Hazard ratio; PRISMA: Preferred Reporting Items for Systematic Reviews and Meta-analysis; BRENDA: "Breast Cancer Care Under Evidence Based Guidelines" retrospective cohort project; TNBC: Triple Negative Breast Cancer

\section{Acknowledgments}

Not applicable.

\section{Authors' contributions}

IRC, AVM, ENDG, JPB, YS, MR, IS, DR, CC, PAC, ZSP, LN, EP were responsible for conducting the systematic review. IRC, DR, IS, CC, LN, EP, PAC contributed to the definition of the research protocol. IS conducted the search. IRC, AVM, ENDG, JPB, YS, MR conducted data extraction and quality appraisal of included studies. ENDG, AVM, JPB conducted the statistical analysis. IRC, ENDG, AVM, JPB, YS, MR, IS, DR, CC, PAC contributed to the interpretation and reporting of the results. IRC and ENDG drafted the first version of the article. All authors reviewed critically and provided comments on subsequent versions of the article. All authors read and approved the final manuscript prior to submission.

\section{Funding}

The systematic review was carried out by the Iberoamerican Cochrane Center under Framework contract 443094 for procurement of services between European Commission Joint Research Centre and Asociación Colaboración Cochrane Iberoamericana.

AVM received a training grant D43 TW007393 Fogarty International Centre of the US National Institutes of Health for the Emerging Diseases and Climate Change Research Unit of the School and Public Health Administration at Universidad Peruana Cayetano Heredia.

\section{Availability of data and materials}

The datasets used and/or analysed during the current study are available from the corresponding author on reasonable request.

\section{Ethics approval and consent to participate}

Not applicable.

\section{Consent for publication}

Not applicable.

\section{Competing interests}

ZP, LN, and EP are current employees of the Joint Research Centre, European Commission.

IRC, ENDG, JPB, YS, MR, IS, DR, CC, PAC are employees of the Iberoamerican Cochrane Center.

\section{Author details}

${ }^{1}$ Balearic Islands Health Research Institute (IdISBa), Palma, Spain. ${ }^{2}$ Primary Care Research Unit of Mallorca, Balearic Islands Health Service, Palma, Spain. ${ }^{3}$ CIBER de Epidemiología y Salud Pública (CIBERESP), Madrid, Spain. ${ }^{4}$ Facultad de Medicina Humana, Universidad Nacional Mayor de San Marcos, Lima, Peru. ${ }^{5}$ Iberoamerican Cochrane Centre - Department of Clinical Epidemiology and Public Health, Biomedical Research Institute Sant Pau (IIB Sant Pau), Sant Antonio María Claret 167, 08025 Barcelona, Spain. IInterdisciplinary Centre for Health Studies (CIESAL), Universidad de Valparaíso, Valparaíso, Chile.

${ }^{7}$ European Commission, Joint Research Centre (JRC), Ispra, Italy.

Received: 7 May 2020 Accepted: 22 September 2020

Published online: 07 October 2020

\section{References}

1. Ferlay J EM, Lam F, Colombet M, Mery L, Piñeros M, Znaor A, Soerjomataram I, Bray F. Global Cancer Observatory: Cancer Today Lyon, France International Agency for Research on Cancer; 2018 [Available from: https://gco.iarc.fr/today.
2. ECIS - European Cancer Information System From https:/ecis.jrc.ec.europa.eu, accessed on 19/08/2019. (c) European Union, 2019.

3. Early Breast Cancer Trialists' Collaborative Group (EBCTCG). Effects of chemotherapy and hormonal therapy for early breast cancer on recurrence and 15-year survival: an overview of the randomised trials. Lancet. 2005; 365(9472):1687-717.

4. Al-Hajj M, Wicha MS, Benito-Hernandez A, Morrison SJ, Clarke MF. Prospective identification of tumorigenic breast cancer cells. Proc Natl Acad Sci U S A. 2003;100(7):3983-8.

5. Slamon DJ, Leyland-Jones B, Shak S, Fuchs H, Paton V, Bajamonde A, et al. Use of chemotherapy plus a monoclonal antibody against HER2 for metastatic breast cancer that overexpresses HER2. N Engl J Med. 2001;344(11):783-92.

6. van de Vijver MJ, He YD, van't Veer LJ, Dai H, Hart AA, Voskuil DW, et al. A gene-expression signature as a predictor of survival in breast cancer. N Engl Med. 2002;347(25):1999-2009.

7. Van't Veer LJ, Dai H, van de Vijver MJ, He YD, Hart AA, Mao M, et al. Gene expression profiling predicts clinical outcome of breast cancer. Nature. 2002; 415(6871):530-6.

8. Berry DA, Cronin KA, Plevritis SK, Fryback DG, Clarke L, Zelen M, et al. Effect of screening and adjuvant therapy on mortality from breast cancer. N Engl J Med. 2005;353(17):1784-92.

9. Gangnon RE, Stout NK, Alagoz O, Hampton JM, Sprague BL, Trentham-Dietz A. Contribution of Breast Cancer to Overall Mortality for US Women. Med Decis Making. 2018;38(1_suppl):24s-31s.

10. Kalager M, Zelen M, Langmark F, Adami HO. Effect of screening mammography on breast-cancer mortality in Norway. N Engl J Med. 2010; 363(13):1203-10.

11. Clinical Practice Guidelines We Can Trust. Washington DC: National Academy Press (US); 2011. Available from: https://www.ncbi.nlm.nih.gov/ books/NBK209546/.

12. Guyatt GH, Oxman AD, Vist GE, Kunz R, Falck-Ytter Y, Alonso-Coello P, et al. GRADE: an emerging consensus on rating quality of evidence and strength of recommendations. BMJ. 2008;336(7650):924-6.

13. Davis DA, Taylor-Vaisey A. Translating guidelines into practice: a systematic review of theoretic concepts, practical experience and research evidence in the adoption of clinical practice guidelines. Can Med Assoc J. 1997;157(4): 408-16.

14. Ford I, Norrie J. Pragmatic trials. N Engl J Med. 2016;375(5):454-63.

15. Gandhi S, Verma S, Ethier JL, Simmons C, Burnett H, Alibhai SM. A systematic review and quality appraisal of international guidelines for early breast cancer systemic therapy: Are recommendations sensitive to different global resources? Breast (Edinburgh, Scotland). 2015;24(4):309-17.

16. Arts DL, Voncken AG, Medlock S, Abu-Hanna A, van Weert HC. Reasons for intentional guideline non-adherence: a systematic review. Int J Med Inform. 2016:89:55-62.

17. Andreano A, Rebora P, Valsecchi MG, Russo AG. Adherence to guidelines and breast cancer patients survival: a population-based cohort study analyzed with a causal inference approach. Breast Cancer Res Treat. 2017; 164(1):119-31.

18. Ebner F, Hancke K, Blettner M, Schwentner L, Wockel A, Kreienberg R, et al. Aggressive intrinsic subtypes in breast Cancer: a predictor of guideline adherence in older patients with breast Cancer? Clin Breast Cancer. 2015; 15(4):e189-95.

19. Ebner F, van Ewijk R, Wockel A, Hancke K, Schwentner L, Fink V, et al. Tumor biology in older breast cancer patients--what is the impact on survival stratified for guideline adherence? A retrospective multi-centre cohort study of 5378 patients. Breast (Edinburgh, Scotland). 2015;24(3):256-62.

20. Wollschlager D, Meng X, Wockel A, Janni W, Kreienberg R, Blettner M, et al. Comorbidity-dependent adherence to guidelines and survival in breast cancer-Is there a role for guideline adherence in comorbid breast cancer patients? A retrospective cohort study with 2137 patients. Breast J. 2018; 24(2):120-7.

21. Jacke CO, Albert US, Kalder M. The adherence paradox: guideline deviations contribute to the increased 5-year survival of breast cancer patients. BMC Cancer. 2015;15:734.

22. Wolters R, Wischhusen J, Stuber T, Weiss CR, Krockberger M, Bartmann C, et al. Guidelines are advantageous, though not essential for improved survival among breast cancer patients. Breast Cancer Res Treat. 2015;152(2):357-66.

23. Riley RD, Hayden JA, Steyerberg EW, Moons KG, Abrams K, Kyzas PA, et al. Prognosis research strategy (PROGRESS) 2: prognostic factor research. PLoS Med. 2013;10(2):e1001380. 
24. Higgins JP, Altman DG, Gotzsche PC, Juni P, Moher D, Oxman AD, et al. The Cochrane Collaboration's tool for assessing risk of bias in randomised trials. BMJ. 2011;343:d5928

25. Moher D, Liberati A, Tetzlaff J, Altman DG, Group P. Preferred reporting items for systematic reviews and meta-analyses: the PRISMA statement. PLoS Med. 2009;6(7):e1000097.

26. Stang A. Critical evaluation of the Newcastle-Ottawa scale for the assessment of the quality of nonrandomized studies in meta-analyses. Eur J Epidemiol. 2010;25(9):603-5.

27. NIH. Quality Assessment Tool for Before-After (Pre-Post) Studies With No Control Group 2014 [Available from: https://www.nhlbi.nih.gov/health-pro/ guidelines/in-develop/cardiovascular-risk-reduction/tools/before-after.

28. DerSimonian R, Laird N. Meta-analysis in clinical trials. Control Clin Trials. 1986;7(3):177-88.

29. Higgins JP, Thompson SG. Quantifying heterogeneity in a meta-analysis. Stat Med. 2002;21(11):1539-58.

30. Wockel A, Wolters R, Wiegel T, Novopashenny I, Janni W, Kreienberg R, et al. The impact of adjuvant radiotherapy on the survival of primary breast cancer patients: a retrospective multicenter cohort study of 8935 subjects. Ann Oncol. 2014;25(3):628-32.

31. Skoetz N, Goldkuhle M, van Dalen EC, Akl EA, Trivella M, Mustafa RA, et al, GRADE guidelines 27: how to calculate absolute effects for time-to-event outcomes in summary of findings tables and evidence profiles. J Clin Epidemiol. 2020;118:124-31.

32. Review Manager (RevMan) Version 5.3. ed. Copenhagen: The Nordic Cochrane Centre, The Cochrane Collaboration; 2014.

33. GRADEpro GDT: GRADEpro Guideline Development Tool [Software]. McMaster University, 2020 (developed by Evidence Prime, Inc.). Available from gradepro.org.

34. Iorio A, Spencer FA, Falavigna M, Alba C, Lang E, Burnand B, et al. Use of GRADE for assessment of evidence about prognosis: rating confidence in estimates of event rates in broad categories of patients. BMJ. 2015;350:h870.

35. Moons KGM, Royston P, Vergouwe $Y$, Grobbee DE, Altman DG. Prognosis and prognostic research: what, why, and how? BMJ. 2009;338:b375.

36. de Roos MA, de Bock GH, Baas PC, de Munck L, Wiggers T, de Vries J. Compliance with guidelines is related to better local recurrence-free survival in ductal carcinoma in situ. Br J Cancer. 2005;93(10):1122-7.

37. Hancke K, Denkinger MD, Konig J, Kurzeder C, Wockel A, Herr D, et al. Standard treatment of female patients with breast cancer decreases substantially for women aged 70 years and older: a German clinical cohort study. Ann Oncol. 2010;21(4):748-53.

38. Mille D, Roy T, Carrere MO, Ray I, Ferdjaoui N, Spath HM, et al. Economic impact of harmonizing medical practices: compliance with clinical practice guidelines in the follow-up of breast cancer in a French Comprehensive Cancer Center. J Clin Oncol. 2000;18(8):1718-24.

39. Poncet B, Colin C, Bachelot T, Jaisson-Hot I, Derain L, Magaud L, et al. Treatment of metastatic breast cancer: a large observational study on adherence to French prescribing guidelines and financial cost of the antiHER2 antibody trastuzumab. Am J Clin Oncol. 2009;32(4):369-74.

40. Sacerdote C, Bordon R, Pitarella S, Mano MP, Baldi I, Casella D, et al. Compliance with clinical practice guidelines for breast cancer treatment: a population-based study of quality-of-care indicators in Italy. BMC Health Serv Res. 2013;13:28.

41. Schwentner L, Wockel A, Konig J, Janni W, Ebner F, Blettner M, et al. Adherence to treatment guidelines and survival in triple-negative breast cancer: a retrospective multi-center cohort study with 9,156 patients. BMC Cancer. 2013;13:487.

42. Schwentner $L$, Wolters $R$, Wischnewsky M, Kreienberg R, Wockel A. Survival of patients with bilateral versus unilateral breast cancer and impact of guideline adherent adjuvant treatment: a multi-centre cohort study of 5292 patients. Breast (Edinburgh, Scotland). 2012;21(2):171-7.

43. Schwentner L, Wolters R, Koretz K, Wischnewsky MB, Kreienberg R, Rottscholl $R$, et al. Triple-negative breast cancer: the impact of guidelineadherent adjuvant treatment on survival--a retrospective multi-Centre cohort study. Breast Cancer Res Treat. 2012;132(3):1073-80.

44. van de Water W, Bastiaannet E, Dekkers OM, de Craen AJ, Westendorp RG, Voogd AC, et al. Adherence to treatment guidelines and survival in patients with early-stage breast cancer by age at diagnosis. Br J Surg. 2012;99(6): 813-20.

45. Van Ewijk R, Wockel A, Gundelach T, Hancke K, Janni W, Singer S, et al. Is guideline-adherent adjuvant treatment an equal alternative for patients aged $>65$ who cannot participate in adjuvant clinical breast cancer trials? A retrospective multi-center cohort study of 4,142 patients. Arch Gynecol Obstet. 2015;291(3):631-40.

46. Varga D, Wischnewsky M, Atassi Z, Wolters R, Geyer V, Strunz K, et al. Does guideline-adherent therapy improve the outcome for early-onset breast cancer patients? Oncology. 2010;78(3-4):189-95.

47. Wockel A, Varga D, Atassi Z, Kurzeder C, Wolters R, Wischnewsky M, et al. Impact of guideline conformity on breast cancer therapy: results of a 13year retrospective cohort study. Onkologie. 2010;33(1-2):21-8.

48. Wockel A, Kurzeder C, Geyer V, Novasphenny I, Wolters R, Wischnewsky M, et al. Effects of guideline adherence in primary breast cancer--a 5-year multi-center cohort study of 3976 patients. Breast (Edinburgh, Scotland). 2010;19(2):120-7.

49. Wimmer T, Ortmann O, Gerken M, Klinkhammer-Schalke M, Koelbl O, Inwald EC. Adherence to guidelines and benefit of adjuvant radiotherapy in patients with invasive breast cancer: results from a large population-based cohort study of a cancer registry. Arch Gynecol Obstet. 2019;299(4):1131-40.

50. Wollschlager D, Meng X, Wockel A, Janni W, Kreienberg R, Blettner M, et al. Comorbidity-dependent adherence to guidelines and survival in breast canceris there a role for guideline adherence in comorbid breast cancer patients? A retrospective cohort study with 2137 patients. Breast J. 2018;24(2):120-7.

51. Henry NL, Hayes DF, Ramsey SD, Hortobagyi GN, Barlow WE, Gralow JR. Promoting quality and evidence-based care in early-stage breast cancer follow-up. J Natl Cancer Inst. 2014;106(4):dju034.

52. Subramanian S, Klosterman M, Amonkar MM, Hunt TL. Adherence with colorectal cancer screening guidelines: a review. Prev Med. 2004;38(5):536-50.

53. Carpentier MY, Vernon SW, Bartholomew LK, Murphy CC, Bluethmann SM. Receipt of recommended surveillance among colorectal cancer survivors: a systematic review. J Cancer Surviv. 2013;7(3):464-83.

54. Ament SM, de Groot JJ, Maessen JM, Dirksen CD, van der Weijden T, Kleijnen J. Sustainability of professionals' adherence to clinical practice guidelines in medical care: a systematic review. BMJ Open. 2015;5(12):e008073.

55. Hoomans T, Evers SM, Ament AJ, Hubben MW, van der Weijden T, Grimshaw JM, et al. The methodological quality of economic evaluations of guideline implementation into clinical practice: a systematic review of empiric studies. Value Health. 2007;10(4):305-16.

56. Ferron G, Martinez A, Gladieff L, Mery E, David I, Delannes M, et al. Adherence to guidelines in gynecologic cancer surgery. Int J Gynecol Cancer. 2014;24(9):1675-8.

57. Bahtsevani C, Uden G, Willman A. Outcomes of evidence-based clinical practice guidelines: a systematic review. Int J Technol Assess Health Care. 2004;20(4):427-33.

58. Grimshaw JM, Russell IT. Effect of clinical guidelines on medical practice: a systematic review of rigorous evaluations. Lancet (London, England). 1993: 342(8883):1317-22.

59. Lugtenberg M, Burgers JS, Westert GP. Effects of evidence-based clinical practice guidelines on quality of care: a systematic review. Qual Saf Health Care. 2009;18(5):385-92.

60. Thomas LH, Cullum NA, McColl E, Rousseau N, Soutter J, Steen N. Guidelines in professions allied to medicine. Cochrane Database Syst Rev. 1999;(1). Art. No.: CD000349. https://doi.org/10.1002/14651858.CD000349.. Available at: https://www.cochranelibrary.com/cdsr/doi/10.1002/14651858.CD000349/full.

61. Worrall G, Chaulk P, Freake D. The effects of clinical practice guidelines on patient outcomes in primary care: a systematic review. CMAJ : Canadian Medical Association journal = journal de l'Association medicale canadienne. 1997;156(12):1705-12.

62. Guyatt GH, Oxman AD, Kunz R, Atkins D, Brozek J, Vist G, et al. GRADE guidelines: 2. Framing the question and deciding on important outcomes. J Clin Epidemiol. 2011;64(4):395-400

63. Schünemann HJ, Lerda D, Dimitrova N, Alonso-Coello P, Gräwingholt A, Quinn C, et al. Methods for development of the European Commission initiative on breast Cancer guidelines: recommendations in the era of guideline TransparencyEuropean commission initiative on breast Cancer guidelines. Ann Intern Med. 2019;171(4):273-80.

64. Haggman-Laitila A, Mattila LR, Melender HL. A systematic review of the outcomes of educational interventions relevant to nurses with simultaneous strategies for guideline implementation. J Clin Nurs. 2017;26(3-4):320-40.

65. Gagliardi AR, Alhabib S. Trends in guideline implementation: a scoping systematic review. Implement Sci. 2015;10:54.

66. Flodgren G, Hall AM, Goulding L, Eccles MP, Grimshaw JM, Leng GC, Shepperd $\mathrm{S}$. Tools developed and disseminated by guideline producers to 
promote the uptake of their guidelines. Cochrane Database Syst Rev. 2016; (8). Art. No.: CD010669. https://doi.org/10.1002/14651858.CD010669.pub2. Available at: https://www.cochranelibrary.com/cdsr/doi/10.1002/14651858. CD010669.pub2/full.

67. Shekelle P, Woolf S, Grimshaw JM, Schunemann HJ, Eccles MP. Developing clinical practice guidelines: reviewing, reporting, and publishing guidelines; updating guidelines; and the emerging issues of enhancing guideline implementability and accounting for comorbid conditions in guideline development. Implement Sci. 2012;7:62.

68. Gagliardi AR, Brouwers MC. Do guidelines offer implementation advice to target users? A systematic review of guideline applicability. BMJ Open. 2015; 5(2):e007047.

69. Grimshaw JM, Thomas RE, MacLennan G, Fraser C, Ramsay CR, Vale L, et al. Effectiveness and efficiency of guideline dissemination and implementation strategies. Health Technol assess (Winchester, England). 2004:8(6):iii-iv, 1-72.

70. Davies $\mathrm{P}$, Walker AE, Grimshaw JM. A systematic review of the use of theory in the design of guideline dissemination and implementation strategies and interpretation of the results of rigorous evaluations. Implement Sci. 2010;5:14.

71. Liang L, Bernhardsson S, Vernooij RW, Armstrong MJ, Bussieres A, Brouwers $M C$, et al. Use of theory to plan or evaluate guideline implementation among physicians: a scoping review. Implement Sci. 2017;12(1):26.

\section{Publisher's Note}

Springer Nature remains neutral with regard to jurisdictional claims in published maps and institutional affiliations.

Ready to submit your research? Choose BMC and benefit from:

- fast, convenient online submission

- thorough peer review by experienced researchers in your field

- rapid publication on acceptance

- support for research data, including large and complex data types

- gold Open Access which fosters wider collaboration and increased citations

- maximum visibility for your research: over $100 \mathrm{M}$ website views per year

At $\mathrm{BMC}$, research is always in progress.

Learn more biomedcentral.com/submissions 